\title{
Glycosylated Haemoglobin and Red Blood Cells in Diabetes
}

Glycosylated haemoglobin has an increased affinity for oxygen [1] and in diabetics the number of red blood cells has been found to correlate with glycohaemoglobin (GHb) level [2]. If confirmed, this could indicate compensatory polycythaemia resulting from chronic hypoxaemia. We have reviewed in this respect our data relating to 79 adult diabetic males and 48 postmenopausal women, all of them living in the coastal area, non-smokers and suffering from no known heart, lung or blood diseases. No differences were found between patients treated by diet alone, oral drugs or insulin. Blood count was done in the Coulter counter, and $\mathrm{GHb}$ was determined by the Biorex 70 column method [3]. Results are presented in the table and show statistically significant but very weak correlation for GHb positively with of red blood cells $(p=0.04)$, and negatively with mean corpuscular volume $(p=0.034)$ in males only.

Table. Red blood cells (RBC), haematocrit, mean corpuscular vo lume (MCV), and glycohaemoglobin $(\mathrm{GHb})$ in diabetics $(\mathrm{M} \pm \mathrm{SD})$

\begin{tabular}{lll}
\hline & Males & Females \\
\hline RBC, $10^{6} / \mathrm{mm}^{3}$ & $5.00 \pm 0.488$ & $4.58 \pm 0.462$ \\
Haematocrit, \% & $44.4 \pm 3.85$ & $40.9 \pm 3.77$ \\
MCV mcm & $89.4 \pm 4.95$ & $89.4 \pm 5.89$ \\
\hline
\end{tabular}

In 21 male patients the tests were repeated after a change in the diabetic control and stabilization of $\mathrm{GHb}$ at another level. No significant correlation was found between the changes in $\mathrm{GHb}$ on the one hand and red blood cell number ( $\mathrm{r}-0.274 ; \mathrm{NS}$ ) or MCV ( $\mathrm{r}-0.012$; NS) on the other.

Our data do not confirm in this indirect way the chronic hypoxic effect of $\mathrm{GHb}$. The changes in the diabetic control as reflected by $\mathrm{GHb}$ were not accompanied by the changes in the opposite direction of $\mathrm{MCV}$ or the changes in the same direction of red blood cell number. The unlikelihood of a significant hypoxic effect of increased $\mathrm{GHb}$ in human diabetes has been pointed out already by Bunn et al. [2].

\section{References}

1. Bunn HF, Briehl RW (1970) The interaction of 2,3-diphosphoglycerate with various human hemoglobins. J Clin Invest 49 ; 1088-1095

2. Bunn HF, Gabbay KH, Gallop PM (1978) The glycosylation of hemoglobin: relevance to diabetes mellitus. Science 200: 21-27

3. Lev-Ran A, Vander Laan WP (1979) Glycohemoglobins and glucose tolerance. JAMA 241: 912-914

4. Graham JJ, Ryall RG, Wise PH (1980) Glycosylated haemoglobin and relative polycythaemia in diabetes mellitus. Diabetologia 18: $205-207$

Arye Lev-Ran, M. D., Ph. D.

Scripps Clinic and Research Foundation

La Jolla, CA 92161, USA

\section{Prevalence of Permanent Congenital Diabetes Mellitus}

\section{The Editor, Diabetologia}

A recent publication by Crossley in Diabetologia furthers our understanding of the epidemiology of juvenile diabetes [1]. Although the increased incidence of juvenile diabetes early in adolescence is well documented in Crossley's and other such reports [2, 3 ], few if any comment on what appears to be a decreased prevalence seen during the first year of life - especially the number of neonates with a permanent congenital insulin-dependent state.

We have cared for a child who had documented hyperglycaemia within his first twenty-four hours, and who continues to require insulin at the age of three years.

Perinatal history revealed the infant was delivered without complication to a 24-year-old gravida 2, para 2 mother after a 38week pregnancy marked by glycosuria during the week prior to delivery. Birth weight was $1.950 \mathrm{~g}$, length was $43.5 \mathrm{~cm}$, and Apgar scores were 6 and 9. The placenta was unremarkable and weighed $510 \mathrm{~g}$.

At $24 \mathrm{~h}$ of age, the infant was noted to have $2 \%$ glycosuria. Blood glucose was $570 \mathrm{mg} / \mathrm{dl}$ and serum electrolytes were normal. An insulin level was $6 \mu \mathrm{U} / \mathrm{ml}$ and TORCH titres were negative.

Initial treatment consisted of intravenous Ringer lactate and $1 / 16$ unit of crystalline insulin administered subcutaneously approximately every $8 \mathrm{~h}$. Daily insulin requirements gradually increased, and the infant was discharged at ten weeks of age on $3 / 8$ unit of $\mathrm{NPH}$ every $12 \mathrm{~h}$ and feedings at $4 \mathrm{~h}$ intervals. His weight upon discharge was $2.400 \mathrm{~g}$, length $45.5 \mathrm{~cm}$, and head circumference $36 \mathrm{~cm}$.

The infant's mother was reported to have a normal glucose tolerance test one week after delivery. The remainder of the family history was negative for diabetes or other endocrinopathies. 
Developmental milestones were somewhat delayed: the infant sat alone at 10 months, walked at 18 months, and had a limited vocabulary at 18 months. At one year of age, his islet cell antibodies were negative. At three years, the child's diabetes was controlled on 1.5 units of crystalline insulin and 3 units of NPH in the morning, and 1.0 unit of crystalline insulin and 1.5 units of NPH in the evening. His height was $90.0 \mathrm{~cm}$, weight $13.0 \mathrm{~kg}$ and head circumference $49.5 \mathrm{~cm}$.

Transient congenital diabetes mellitus seems unlikely since that condition usually resolves within two to three months, with the most prolonged reported case being 18 months [4].

Prior to our case, the youngest known case of juvenile diabetes mellitus was a $60 \mathrm{~h}$ infant reported by Greenwood [5]. It is interesting to note that our patient, as well as Greenwood's, was small for gestational age. These two cases and their catch-up growth subsequent to beginning insulin, support the concept of insulin's playing a role in regulating fetal growth [6].

The sparsity of case reports of permanent congenital diabetes mellitus $[7,8,9]$, as well as incidence and prevalence studies of juvenile diabetes from various parts of the world, appears to confirm that the lowest prevalence of this condition occurs within the first month of life. In view of the recognized heterogeneity in diabetes mellitus, such observations - although rare - have definite importance in elucidating the aetiology and natural history.

Yours sincerely,

W. H. Hoffman, C. Khoury, H. A. Byrd

\section{References}

1. Crossley JR, Upsdell M (1980) The incidence of juvenile diabetes mellitus in New Zealand. Diabetologia 18: 29-34

2. Bloom A, Hayes TM, Gamble DR (1975) Register of newly diagnosed diabetic children. Br Med J III: 580-583

3. North AF, Gorwitz K, Sultz HA (1977) A secular increase in the incidence of juvenile diabetes mellitus. J Pediatr 91: 706-710

4. Hutchison JH, Keay AJ, Kerr MM (1962) Congenital temporary diabetes mellitus. Br Med J II: 436-440

5. Greenwood RD, Traisman HS (1971) Permanent diabetes mellitus in a neonate. J Pediatr 79: 296-298

6. Dodge JA, Laurence KM (1977) Congenital absence of islets of Langerhans. Arch Dis Childh 52: 411-413

7. Guest GM (1949) Diabetes mellitus in early infancy, without dietary restrictions. Acta Paediatr Scand 38: 196-208

8. Lewis SR, Mortimer PE (1964) Idiopathic neonatal hyperglycaemia. Arch Dis Childh 39: 618-624

9. Greenwood RD, op. cit.

Dr. William H. Hoffman

Children's Hospital of Michigan

Wayne State University

Detroit, MI 48201, USA

\section{Interpretation of the Glucose Tolerance Test}

Dear Sir,

The need for meaningful criteria by which to interpret the glucose tolerance test (GTT) has been described by many experts [1-4]. It is the purpose of this letter to describe a flaw in criteria recently recommended by an international workgroup sponsored by the National Diabetes Data Group (NDDG) of the National Institutes of Health [4]. The plasma glucose concentration recommended as diagnostic of overt diabetes is a $2 \mathrm{~h}$ value and at least one point between the fasting and $2 \mathrm{~h}$ value exceeding $200 \mathrm{mg} /$ $100 \mathrm{ml}$ on more than one occasion. The problem is the requirement that the abnormal GTT apply on more than one occasion. The GTT is expensive, inconvenient, and stressful, and many physicians are reluctant to require a repeat performance. Diagnostic decisions are often made on the basis of a single GTT. But the NDDG has no classification for subjects who fullfill the criteria for a diabetic GTT on only one occasion. The NDDG defines impaired glucose tolerance as a single GTT with a $2 \mathrm{~h}$ value between 140 and $200 \mathrm{mg} / 100 \mathrm{ml}$ and one point between the fasting and $2 \mathrm{~h}$ value exceeding $200 \mathrm{mg} / 100 \mathrm{ml}$. By leaving a gap between criteria for overt diabetes and impaired glucose tolerance, the NDDG has clearly established a borderline area, although ostensibly rejecting attempts to define borderline diabetes. Subjects exhibiting an overt diabetic GTT on only one occasion exist in this borderline area. They cannot be classified as overt diabetics because the GTT was performed only once, and they cannot be classified as having impaired glucose tolerance because the $2 \mathrm{~h}$ value exceeds $200 \mathrm{mg}$ per $100 \mathrm{ml}$. The tendency among many community physicians will be to interpret the single diabetic GTT as diagnostic of overt diabetes. This tendency is indeed fostered by the NDDG which states the criteria for a diabetic GTT in the summary of their report but omits the phrase "on more than one occasion" [4].

The criteria for interpreting the GTT should be clear. If borderline diabetes is to be ignored, the gap between criteria for overt diabetes and impaired glucose tolerance should be removed. Im- paired glucose tolerance could be defined as anything less than the criteria for an overt diabetic GTT.

Alternatively, the gap between criteria for an overt diabetic GTT and impaired glucose tolerance might be preserved and defined as the criteria for borderline diabetes. Certainly the majority of patients with noninsulin-dependent diabetes pass through a precursor stage of overt disease. Although the GTT is unreliable in detecting this precursor stage, it might be wise to allow for the possibility that the GTT in combination with other tests, such as glycosylated haemoglobin, could detect borderline diabetes with adequate accuracy [5].

Yours sincerely,

D. Dix and P. Cohen

\section{References}

1. Keen H, Jarrett RJ, Alberti KGMM (1980) Diabetes mellitus: a new look at diagnostic criteria. Diabetologia 18: 81

2. Keen H, Jarrett RJ, Alberti KGMM (1979) Diabetes mellitus: a new look at diagnostic criteria. Diabetologia 16: 283-285

3. Siperstein MD (1975) The glucose tolerance test: a pitfall in the diagnosis of diabetes mellitus. Adv Intern Med 20: 297-323

4. National Diabetes Data Group (1979) Classification and diagnosis of diabetes mellitus and other categories of glucose intolerance. Diabetes 28: 1039

5. Dix D, Cohen P, Kingsley S, Senkbeil J, Sexton K (1979) Glycohemoglobin and glucose tolerance tests compared as indicators of borderline diabetes. Clin Chem 25: 877

D. Dix, P. Cohen

Department of Biology and Health Science

University of Hartford

West Hartford, CT 06117, USA 